\title{
Comparison of two drying methods of mango (oven and solar drying)
}

\begin{abstract}
Two drying methods (solar and oven) were used to dry a variety of mango. We have a drying yield of $33 \%$ for sun dried mango versus $26 \%$ for oven dried mango; Relative humidity is $14.17 \% \pm 0.01$ for sun dried mango compared with $8.25 \% \pm 0.01$ for oven dried mango. We observe a decrease in dry matter for the sun-dried mango compared to oven dried mango. Mango, dried in the sun has a high concentration of vitamin B6, vitamin $\mathrm{C}$ and mineral elements $(\mathrm{Ca}, \mathrm{Mg}$ and $\mathrm{Fe})$. But we also noted the presence of vitamins (A, D and E) after the drying operations. Concerning the microbiological parameters, we obtained results meeting the limits set by the ISO 4833 standard which governs the microbiology of the food chain. The method of solar drying in view of the results obtained proves to be the one that boosts the nutritional properties of mango.
\end{abstract}

Keywords: mango, oven, solar dryer, vitamins, proteins, minerals
Volume 5 Issue I - 2017

\author{
Izaora Mwamba,' Karl Tshimenga,' Jean- \\ Kayolo,' Laurette Mulumba,' Gauthier \\ Gitago, ${ }^{2}$ Christina Mputu Tshibad, ${ }^{2}$ Jean Noël \\ Mputu Kanyinda' \\ 'Department of Chemistry and Industry, Biochemistry and Food \\ Chemistry Unit, University of Kinshasa, DR Congo \\ ${ }^{2}$ Microbiological and Physico-Chemical Laboratory, DR Congo \\ ${ }^{3}$ Clinic of Hematology and Oncology, DR Congo
}
Correspondence: Mputu Kanyinda Jean Noël,Associate Professor University of Kinshasa, Faculty of Sciences, Department of Chemistry, Food and Biochemistry Unit, I University street BP 190 Kinshasa, DR Congo, Tel +243977652525, Email kanyinda2004@gmail.com

Received: September 19, 2017 | Published: October 17, 2017

\begin{abstract}
Abbreviations: AAS, atomic absorption spectrometry; AOAC, association of official analytical chemists; MDO, mango dried in the oven; MDS, mango dried in the sun; PCA, plate count agar; $\mathrm{pH}$, hydrogen potential

\section{Introduction}

The mango (fruit of Mangifera indica), is produced in abundance in Central Africa generally and in the Democratic Republic of the Congo in particular. With a period of relatively short harvest approximately 3 months a year because of the regions, its availability during harvest periods is problematic. ${ }^{1}$ During the harvest period, the quantities of mangoes available on the markets are important and losses are considerable. ${ }^{2,3}$
\end{abstract}

At room temperature, a fresh mango keeps less than ten days. It supports badly the freezing and undergoes browning reactions when it is cooled during a rather long period. It arises of than a real concern for the preservation of the mango. They exist several techniques to transform the mango (juice, jam etc). ${ }^{4}$ But in rural areas, the preservation of juices and the jams come up against problems of refrigeration because of the lack of electricity.

The previous works ${ }^{2}$ showed that the drying of the mango is an interesting and practical alternative in rural areas. Indeed, the drying is a technique of dehydration, which allows eliminating partially or totally the liquid soaking a solid. This rather former technique is nowadays very used in developing countries for the preservation of food..$^{5-7}$

In the Democratic Republic of Congo, the drying is easy because of the favorable conditions of period of sunshine, temperature and relative humidity. The drying of the mango appears as an interesting alternative to reduce the losses post harvest. ${ }^{8}$ Numerous studies show that the dried mango would constitute one of the best alternatives in medicine to fight and warn the deficiency in vitamin A in dry periods. ${ }^{9}$
This work aimed at the comparison of two methods of drying of the mango (oven and solar dryer to choose the method the most adapted for the drying of mangoes in rural areas.

\section{Material and methods}

\section{Material}

Mangos: Mangoes are from the local market of Masina Pascal a district is from the city of Kinshasa. The fruits used fruits were without wounds and had a weight of $243 \pm 13 \mathrm{~g}$; they had a commercial maturity not too ripe.

Equipment of drying: The operations of drying took place in an oven BINDER and on a solar dryer. The solar dryer is made of metal, it has 6 sides with glass on 5 sides, the sieves inside are used for the reception of the samples to be dried and the thermometer incorporated allows to follow the temperature evolution. The sample in the solar dryer is isolated the outside environment (flies, bees, dusts). The temperature of drying in the oven was fixed in $50^{\circ} \mathrm{C}$ whereas in the solar dryer it varied daily at $22.4^{\circ} \mathrm{C}$ to $40.7^{\circ} \mathrm{C}$.

\section{Methods}

Sample processing: The fruits used are of the so-called Kent variety. The selected mangoes are washed with potable water, drained and weighed. After pelage and coring, they are cut into strips.

Drying of mangoes: The mango slices are placed on the racks so as to leave space between them to facilitate the circulation of the air. The drying is ensured by the hot air which passes parallel to the layers of the exposed lamellae. The heat is transferred to the mango slats by convection while the water is removed by drive at the dry air which enters from the bottom and emerges from the top. The slides are turned three times during drying. This operation allows mangoes slats not to stick on the racks. Mango slat is deemed dry when their weight doesn't vary considerably ${ }^{10}$ (Sawadogo). 
Physicochemical and biochemical analysis of mangoes: The relative humidity is determined in an oven at $105^{\circ} \mathrm{C}$ for 24 hours. ${ }^{11}$ The $\mathrm{pH}$ of our samples of fresh and dried mangoes is obtained using the $\mathrm{pH}$ meter. Total ash was determined by calcination in a muffle furnace at $600{ }^{\circ} \mathrm{C} 24 \mathrm{~h} .{ }^{12}$ The butterfat is obtained by extraction with a Soxhlet using petroleum ether. The density is obtained with a densimeter. Total sugars are determined by a leading refractometer Abbot. ${ }^{13}$ Citric acid and vitamin $\mathrm{C}$ were determined by titrimetric dosing, protein was determined by Kjeldahl method. ${ }^{14}$ Vitamin B6 was determined also; vitamins $\mathrm{A}, \mathrm{D}$ and $\mathrm{E}$ were identified by spectrometry. The mineral elements are determined by complexometry and by atomic absorption spectrometry (AAS).

Microbiological analysis: Mesophilic, osmophilic and mesophilic germs were respectively determined by using pate count agar (PCA); PCA osm and Sabouraud chl. Salmonella, Staphylococcus and Coli forms are identified using Selenite, Baird Parker and Chromo medium respectively.

Sensory analysis: The dried slices of mango were submitted to two chemical engineers for appreciation, according to an index form on which are registered the following notes: smell, taste and color.

Statistical analysis: Results are expressed as means with standard deviations of analysis performed in triplicate. Analysis of the variance was done by the Origin pro 8.1 software. ${ }^{13}$

\section{Results}

\section{Determination of physico-chemical, biochemical and microbiological parameters}

Drying kinetics: According to this graph, we observe that the drying in the oven is much faster than the solar drying; because in the oven the temperature is fixed and controlled in at $50^{\circ} \mathrm{C}$. The loss of water is more pronounced during the first 8hours of drying and after 24hours we have more weight evolution. While for mango, dried in the sun, the water loss is more pronounced than after 24 hours and this because of the temperature variations in the solar dryer between $20^{\circ} \mathrm{C}$ and $41^{\circ} \mathrm{C}$; this is why the exposure time is longer than in the oven. After drying, the samples were packaged in heat-welded polyethylene bags; labeled and stored at room temperature for 90days. After 90days, an evaluation of the effectiveness of these two drying methods was carried out by comparing the physico-chemical, microbiological and organoleptic characteristics of the dried mangoes. Overall, there are no significant changes in our two samples. The only marked change is observed in sun-dried mango, which has a fungal contamination after 90days.

Physico-chemical and biochemical analysis: The results of the physicochemical and biochemical analysis of the mangoes analyzed are summarized in the Table 1 . This Table gives the results of the analysis carried out on our samples of mango. We observe that dried mango in the oven at a relatively low relative humidity of $8.25 \%$ compared to sun-dried mango which is $14.17 \%$. This is explained by the temperature that is controlled in the oven, but not in the sun. These values are better than those found by Kameni ${ }^{2}$ (about $15 \%)$. Regarding the ash content, solar drying gives a value of $1.59 \%$ less compared to $2.21 \%$ found for drying in the oven, which is close to the found by Millogo Dè Pierre Damien ${ }^{15}(2.32 \%)$. Mango is poor in fat; we have $2.46 \%$ for fresh mango, $2.58 \%$ for oven dried mango and $1.66 \%$ for sun-dried mango. Our results are better than Sawadogo results.
Concerning the density, the mango dried in the sun to a value greater than that of the dried mango in the oven respectively 0.89 against 0.78 . Our variety of mango is rich in sugar $68.52^{\circ} \mathrm{Brix}$, after drying in the oven we have $52.02^{\circ}$ Brix against $22.36^{\circ} \mathrm{C}$ in the solar dryer. This difference in values is due to sun exposure time and nonenzymatic browning reactions mainly the Maillard reactions. The $\mathrm{pH}$ and titratable acidity of mango, dried in the sun are low compared to dried mango in the oven. The fresh mango is more acidic than those dried in the sun and in the oven. This acidity has a beneficial effect on the preservation and inhibits the proliferation of microorganisms. The proteins were determined by the Kjeldahl method, the oven dried mango with a protein rate of $1.65 \%$ as against $2.65 \%$ for that dried in the sun. The beneficial effect of drying is shown by an increase in the percentage of protein in the samples of dried mangoes compared to that of fresh mango which is $0.86 \%$. This increase is due to a concentration of the proteins by the loss of water on the one hand and by the biochemical reactions favorable to the protein increase on the other hand.

Vitamins: Results of vitamins analysis are given in Tables 2 \& Table 3 . Only the water-soluble vitamins were dosed in this work. We observe that mango, dried in the sun have a higher concentration of vitamin C, $205.4 \mathrm{mg} / 100 \mathrm{ml}$ comparatively of the mango dried in an oven $64.8 \mathrm{mg} / 100 \mathrm{ml}$. On the other hand, the concentration of vitamin B6 in mango, dried in the sun is $69.7 \mathrm{mg} / 100 \mathrm{ml}$, which is the lower than that of oven dried mango $139.5 \mathrm{mg} / 100 \mathrm{ml}$. This is justified for vitamin $\mathrm{C}$ by Maillard reactions which degrade it according to the conditions are favorable or not. Thus, we find that drying mangoes in the oven favor Maillard reactions.

Identification of vitamins A, D and E: The Table 3 below shows the results of the vitamins identified in our mango samples. We identified vitamins $\mathrm{A}, \mathrm{D}$ and $\mathrm{E}$ in our dried mango samples. Regarding the positive result, we can say that drying does not affect the various identifiable vitamins of our mango samples.

Dosage of mineral elements: Table 4 shows the concentrations of certain minerals $(\mathrm{Ca}, \mathrm{Fe}$ and $\mathrm{Mg})$ in our mango test samples. The concentration of magnesium is almost identical for the two drying modes $10.70 \mathrm{mg} / \mathrm{L}$ for dried mango in the oven against $10.64 \mathrm{mg} / \mathrm{L}$ for that dried in the sun. The Calcium concentration is superior in the solar dryer $11 \mathrm{mg} / \mathrm{L}$ compared with $9 \mathrm{mg} / \mathrm{L}$ in the oven. As for the iron concentration, we have a concentration of $0.11 \mathrm{mg} / \mathrm{L}$ in the oven against $0.08 \mathrm{mg} / \mathrm{L}$ in the solar dryer. The concentration of iron is higher after drying in the oven as demonstrated by Sawadogo et al. ${ }^{4}$ which found an average value of between 7 and $20 \mathrm{mg} / 100 \mathrm{~g}$ of iron.

\section{Microbiological analysis}

Mangoes dried in the oven and in the sun: Table 5 gives the results of the microbiological analysis of our oven dried and sun-dried mango samples. For positive cultures (PCA and Osm PCA) the germs found are coccobacilli and sporulate bacilli which are of Gram-positive bacteria. In view of these microbiological results, we refer to the ISO 4833 standard governing the microbiology of the food chain, the oven-dried mango is free from any contamination. Not contamination found after drying and after 3 months of storage at room temperature. However, for mango, dried in the sun, the results are in accordance with standard ISO 4833, with the exception of fungal organisms whose value exceeds the maximum limit. 
Sensory analysis of dried mangoes in the oven and in the sun: The results of the organoleptic analysis are reported in Table 6 . The Table 6 above gives the results of the organoleptic analysis performed on our mango samples. A panel of specialists from the OCC laboratory was set up for evaluations. According to this table, it can be said that from the point of view of odor, taste and texture there is no difference between oven-dried and sun-dried samples. The only difference observed is the color, it is brown for the sample dried in the sun; this brown coloration is probably called the non-enzymatic browning reaction due to heat.

Table I Physico-chemical and biochemical results

\begin{tabular}{llll}
\hline \multirow{2}{*}{ Parameters Studied } & \multicolumn{2}{c}{ Echantillons } & \\
\cline { 2 - 4 } & Fresh Mango & Mango dried in an oven (MDO) & Mango dried in the sun (MDS) \\
\hline Drying yield \% & 26 & 33 \\
Humidity \% & $88,26 \pm 0,01$ & $8,25 \pm 0,01$ & $14,17 \pm 0,01$ \\
Ash \% & $2,63 \pm 0,14$ & $2,21 \pm 0,02$ & $1,59 \pm 0,04$ \\
Fat \% & $2,46 \pm 0,01$ & $2,58 \pm 0,02$ & $1,66 \pm 0,02$ \\
Density & $1,08 \pm 0,01$ & $0,78 \pm 0,01$ & $0,89 \pm 0,01$ \\
Total sugars ${ }^{\circ}$ brix & $68,52 \pm 0,01$ & $52,02 \pm 0,01$ & $22,36 \pm 0,01$ \\
pH & $3,71 \pm 0,01$ & $3,09 \pm 0,01$ & $4,11 \pm 0,01$ \\
Citric acidity \% & $0,86 \pm 0,03$ & $1,65 \pm 0,01$ & $2,65 \pm 0,01$ \\
Crude protein \% & $0,86 \pm 0,04$ & $1,65 \pm 0,01$ & $2,65 \pm 0,03$ \\
\hline
\end{tabular}

Table 2 Vitamin $\mathrm{C}$ and $\mathrm{B} 6$ concentration

\begin{tabular}{lll}
\hline Samples & Vitamin C $(\mathbf{m g} / \mathbf{1 0 0 m l})$ & Vitamin B6 $(\mathbf{m g} / \mathbf{1 0 0 m l})$ \\
\hline Fresh mango & $100,8 \pm 0,30$ & $22,2 \pm 0,01$ \\
Mango dried in an oven & $64,8 \pm 0,20$ & $139,5 \pm 0,43$ \\
Mango dried in the sun & $205,4 \pm 0,10$ & $69,7 \pm 0,12$ \\
\hline
\end{tabular}

Table 3 Identification of vitamins

\begin{tabular}{ll}
\hline Samples & Vitamins A, D et E \\
\hline Fresh mango & + \\
Mango dried in an oven & + \\
Mango dried in the sun & + \\
\hline
\end{tabular}

Table 4 The mineral content of our analyzed mango samples

\begin{tabular}{llll}
\hline Samples & $\mathbf{C a}^{++}(\mathbf{m g} / \mathbf{L})$ & $\mathbf{M g}^{++}(\mathbf{m g} / \mathbf{L})$ & $\mathbf{F e}(\mathbf{m g} / \mathbf{L})$ \\
\hline Fresh mango & $9,74 \pm 0,06$ & $10,66 \pm 0,04$ & $1,066 \pm 0,06$ \\
Mango dried in an oven & $9,08 \pm 0,01$ & $10,70 \pm 0,02$ & $0,116 \pm 0,14$ \\
Mango dried in the sun & $11 \pm 0,14$ & $10,64 \pm 0,04$ & $0,08 \pm 0,04$ \\
\hline
\end{tabular}

Table 5 Results of microbiological analysis of oven-dried mangoes and sun

\begin{tabular}{lllll}
\hline Germs & Maximum limit & Mango dried in the sun & Mango dried in an oven & Culture medium \\
\hline Mesophilic germ & $5.10^{5}$ & 8.103 & 0 & PCA \\
Osmophilic germ & $5.10^{5}$ & 8.103 & 0 & PCA osm \\
Fungal germ & $5.10^{2}-10^{3}$ & 7.103 & 0 & Sabouraud chl. \\
Salmonella & Absence & 0 & 0 & Selenite \\
Staphylococcus & $10^{2}$ & 0 & 0 & Baird Parker \\
Coliforms & $10^{3}$ & 0 & 0 & Chromo \\
\hline
\end{tabular}


Table 6 Results of sensory analysis of dried mangoes in the oven and in the Sun

\begin{tabular}{lllll}
\hline Samples & Odor & Taste & Color & Texture \\
\hline MDO & Fresh mango & Sweetened-acidulated & Brown & Flexible, tacky, dry \\
MDS & Fresh mango & Sweetened-acidulated & Yellow-Brown & Flexible, tacky, dry \\
\hline
\end{tabular}

Yellow-Brown, means that in the package there are more yellow than brown stripes.

Sweetened-acidulated, over perceived more sweet taste than acid taste.

\section{Conclusion}

The solar drying of the mangoes is possible and gives acceptable results compared to the results of dried mango in an oven where the temperature is controlled. From the physicochemical and biochemical point of view, solar drying of the mango boosts a number of nutrients that we encounter in fresh mango, including vitamins, minerals, proteins, etc. In the microbiological aspect, oven-dried mango is more stable after 90days storage at room temperature and free from contamination, while sun-dried mango shows contamination of fungal germs after 90days of storage. The latter is due to transport and storage conditions. In view of all the above, apart from the fungal contamination which we can correct, we argue that the solar drying of the mango has a beneficial effect on human health. This solar drying technology is transferable to farmers to reduce post-harvest losses and boost their savings.

\section{Acknowledgement}

The authors are grateful to the Congolese Office of Control and Professor Efoto Department of Physic for their material support.

\section{Conflicts of interest}

The author declares no conflict of interest.

\section{References}

1. Tounkara LS, Cheik B, Cissé N, et al. Reduction of postharvest losses of mango by the production of vinegar. Institute of Food Technology, University of Liège, Walloon center for food technology. CWBI; 2011. $8 \mathrm{p}$.

2. Kameni A, Mbofung CM, Ngnamtam Z, et al. Ability to dry a few varieties of mango grown in Cameroon. Amélie, Zill, Irwin et Horé Wandou. Proceedings of the symposium, Mai, Garoua, Cameroon; 2002. p. 27-31.

3. Louis Ban Koffi. Directory of mango and pineapple processing technologies and processes. Rome, Italy: FAO; 2008.
4. Sawadogo GH, Traore AS. Chemical composition and nutritional value of burkina faso amelie amelie mango (Mangifera indica L.). $J$ Sci. 2001;2:35-39.

5. Ferradji A, Goudjal Y, Malek A. Drying of grapes of Sultanine variety by a solar dryer with forced convection and a dryer of shell type. Review of Renewable Energies SMSTS'08 Alger. 2008. p. 177-185.

6. Touzi A, Merzaia Blama A. The conservation of foodstuffs by drying in the Saharan regions. Review of Renewable Energies SMSTS'08 Alger. 2008. p. 267-272.

7. Bahlouli F, Tiaiba A, Slamani A. Study of the different drying methods of apricot, update on traditional drying methods in the Hoenn region. M'Sila wilaya; 2008

8. Boulemtafes A. Solar drying of agricultural products. Research and development. Alger: Unpublished; 2014.

9. Boulemtafes A. Energy and Energy analysis of the solar drying process of Mint 1st Conference \& Exhibition Impact of Integrated Clean Energy on the Future of the Mediterranean. Beirut Lebanon; 2011.

10. FAO. Major food and agricultural commodities and producer. Fao Rome, Italy; 2005.

11. Official Methods of Analysis of AOAC International. In: William Horwitz. 18th ed. Curent Throug revision 2007, AOAC; 2005.

12. Motsara MR, Roy NR. Guide to laboratory establishment fort plant nutrient analysis. Rome, Italy: FAO; 2008. p. 1-220.

13. Mbungu $\mathrm{C}$, Tshimenga $\mathrm{K}$, Nsambu $\mathrm{P}$, et al. Microbiological Quality, Biochemical and Physical-Chemical characteristics of artisanal vinegar based piers mangoes. International Journal of Innovation and Applied Studies. 2016;17(3):947-953.

14. AFNOR Determination of total nitrogen content and calculation of the protein content; 2006.

15. Millogo Dè Pierre Damien. Physico-chemical characterization of dried Biological mango (Amélie variety). Burkina Faso; 2011. 54 p. 